Mohammad Baghani, Mahmood Aliofkhazraei*, Amir Seyfoori and Mehdi Askari

\title{
Mechanical alloying of CuFe-alumina nanocomposite: study of microstructure, corrosion, and wear properties
}

https://doi.org/10.1515/secm-2016-0313

Received October 21, 2016; accepted October 16, 2017; previously published online November 28, 2017

\begin{abstract}
The effects of adding $\mathrm{Al}_{2} \mathrm{O}_{3}$ nanoparticles on the microstructure, tribological, magnetic, and corrosion properties of $\mathrm{CuFe}-\mathrm{Al}_{2} \mathrm{O}_{3}$ nanocomposites were investigated in this work. The mixture of $\mathrm{Cu}-25$ wt.\% Fe powder with 5 vol. $\% \mathrm{Al}_{2} \mathrm{O}_{3}$ was mechanically milled. X-ray diffraction results revealed that after $60 \mathrm{~h}$ of mechanical alloying, CuFe solid solution was formed. Magnetic hysteresis loops of the mechanically alloyed powders were extracted at room temperature. The morphology and elemental analysis of the sintered specimens were studied by field emission scanning electron microscope (SEM). It was observed that uniform distribution and embedding of $\mathrm{Al}_{2} \mathrm{O}_{3}$ nanoparticles in the CuFe alloy matrix in nanocomposites were achieved, which exhibited excellent performances. Tribological properties were evaluated through a pinon-disk wear test, and it was found that by the addition of $\mathrm{Al}_{2} \mathrm{O}_{3}$ nanoparticles to $\mathrm{CuFe}$ alloy, the weight loss rate was reduced by $30 \%$. The existence of $\mathrm{Al}_{2} \mathrm{O}_{3}$ nanoparticles in the matrix of $\mathrm{CuFe}$ alloy causes the wear mechanism change from adhesive to abrasive, which means a considerable wear resistance was obtained in nanocomposites. The corrosion properties of the sintered samples in a solution of $3.5 \% \mathrm{NaCl}$ were studied by potentiodynamic polarization. With the addition of $\mathrm{Al}_{2} \mathrm{O}_{3}$ nanoparticles, the corrosion rate of the alloy was reduced by $75 \%$.
\end{abstract}

Keywords: corrosion; mechanical alloying; nanocomposite; tribological properties; wear.

\footnotetext{
*Corresponding author: Mahmood Aliofkhazraei, Department of Materials Science, Faculty of Engineering, Tarbiat Modares University, P.O. Box: 14115-143, Tehran, Iran, e-mail:maliofkh@gmail.com; khazraei@modares.ac.ir Mohammad Baghani and Mehdi Askari: Department of Materials Science, Faculty of Engineering, Tarbiat Modares University, Tehran, Iran

Amir Seyfoori: School of Metallurgy and Materials Engineering, College of Engineering, University of Tehran, Tehran, Iran
}

\section{Introduction}

Because of its magnetic properties, relatively good corrosion resistance, high strength and high electrical conductivity, and low cost of iron compared to other alloying elements, CuFe alloys are receiving much attention by researchers [1]. Besides, because of their excess positive mixing enthalpy, $\mathrm{Cu}$-Fe systems have a low solid solubility (about 3\%) at temperatures below $700^{\circ} \mathrm{C}$. Therefore, they are realized as a binary system with low solid solubility at room temperature [2]. In the $\mathrm{Cu}_{1-\mathrm{x}}-\mathrm{Fe}_{\mathrm{x}}$ system, for $\mathrm{x}<0.6$, the solid solution includes single-phase FCC and for the ones $>0.8$ solid solution, BCC is achieved. For an approximate $x$ range of 0.6-0.8, either of two FCC and BCC phases can be observed in solid solution [3]. In the conducted studies, the preparation of $\mathrm{CuFe}$ alloys was reported by various methods such as vapor deposition [4], high-pressure torsion [5], casting plus mechanical reclamation [6], electrodeposition [7], and mechanical alloying. The nonequilibrium mechanical alloying process can increase the range of solid dissolution in CuFe metastable alloy $[8,9]$. Ueda et al. [10] reported the preparation of CuFe alloy with the methods of mechanical alloying and electrodeposition. The magnetizability behavior relative to the composition had the same behavior for the films produced by electroplating and mechanical alloying samples. The magnetizability curve in the electroplating film of the ferromagnetic hysteresis curve, in contrast with the alloying sample, indicates no hysteresis. Azabou et al. [11] reported the synthesis of $\mathrm{Cu}$-Fe FCC and BCC metastable solid solution with the utilization of high-energy ball mill. Adding $\mathrm{Al}_{2} \mathrm{O}_{3}$ hard particles to copper-based alloys as a reinforcing phase has risen the production rate of nanocomposites with better thermal and electrical conductivity properties, higher wear resistance, thermal stability, and better fatigue behavior than non-reinforced copper alloys. Copper-based composites reinforced with $\mathrm{Al}_{2} \mathrm{O}_{3}$ particles possess high fracture toughness where the fracture toughness, itself, increases by reducing the size of $\mathrm{Al}_{2} \mathrm{O}_{3}$ particles. It is reported that these properties emerge due to the lack of copper-based grain boundaries with $\mathrm{Al}_{2} \mathrm{O}_{3}$ particles. Unlike melting techniques, mechanical alloying 
is optimal in even distribution of particles in the metallic matrix [12]. Welding and fracture of particles during the mechanical alloying process leads to the fusing of a large amount of reinforcing phase within each metallic particle in the solid state and formation of composite particles [13]. Hwang and Lee [14] suggested the production of copper-alumina nanocomposite by the mechanochemical method through the mechanical milling of $\mathrm{CuO}_{2}, \mathrm{Cu}$, and Al powders. Copper-alumina nanocomposites have been successfully manufactured with different percentages of $\mathrm{Al}_{2} \mathrm{O}_{3}$. The powder milled was hot pressed at a temperature of $800^{\circ} \mathrm{C}$. By increasing the percentage of $\mathrm{Al}_{2} \mathrm{O}_{3}$, the hardness of hot-pressed samples was raised from 70 through 103 Rockwell-C. The physical and mechanical properties of the nanocomposites are dependent on the volume fraction and the size of the reinforcing phase nanoparticles, the uniformity distribution of these nanoparticles in the metallic matrix, and the bonding between the reinforcing nanoparticles and metallic matrix [15].

In the present study, the effect of adding $\mathrm{Al}_{2} \mathrm{O}_{3}$ nanoparticles on the microstructure, magnetic, tribological, and corrosion properties of $\mathrm{CuFe}-\mathrm{Al}_{2} \mathrm{O}_{3}$ nanocomposites was investigated. A mixture of copper and iron powders with 0 and $5 \%$.vol $\mathrm{Al}_{2} \mathrm{O}_{3}$ powder as a raw material was accomplished in a satellite ball mill, and then, green compact was prepared by hydraulic press (Pars Hydraulic, Tehran, Iran) and sintered in a furnace. Hardness and pin-on-disk wear tests were implemented in order to investigate the effects of adding $\mathrm{Al}_{2} \mathrm{O}_{3}$ nanoparticles on the mechanical and tribological properties. Cyclic potentiodynamic polarization test was performed for the assessment of the $\mathrm{Al}_{2} \mathrm{O}_{3}$ nanoparticle effects on the corrosion properties of the sintered samples in $3.5 \% \mathrm{NaCl}$ solution.

\section{Research methodology}

Copper and iron powders (Pourian-chemical, Germany) were mixed, respectively, with mean particle sizes of 20 and $50 \mu \mathrm{m}$ for the production of CuFe alloy with a composition of $\mathrm{Cu}-25$ wt.\% Fe. For mechanical alloying and determination of the effect of adding $\mathrm{Al}_{2} \mathrm{O}_{3}$ nanoparticles (Sigma Aldrich, MO, USA), the mixture of $\mathrm{Cu}-25 \mathrm{wt} \% \mathrm{Fe}$ powder with 0 and 5 vol.\% of $\mathrm{Al}_{2} \mathrm{O}_{3}$ nanoparticles was taken under mechanical alloying process using a satellite ball mill (Amin Asia, Tehran, Iran) under argon atmosphere. The duration of milling was $60 \mathrm{~h}$, ball-to-powder weight ratio was 10:1 (total consumed powder was $30 \mathrm{~g}$ ), and rotating speed was $300 \mathrm{rpm}$. One milliliter of ethanol as a process-controlling agent (PCA) was added in order to overcome the problem of adhesion of the powders to the balls and container. To review the formation of the phases, X-ray diffraction (XRD) (Philips, Amsterdam, Netherlands) by X'Pert MPD Philips device with Cok $\alpha$ beam and a wavelength of $1.789 \AA$ was used. Morphologies of the powders

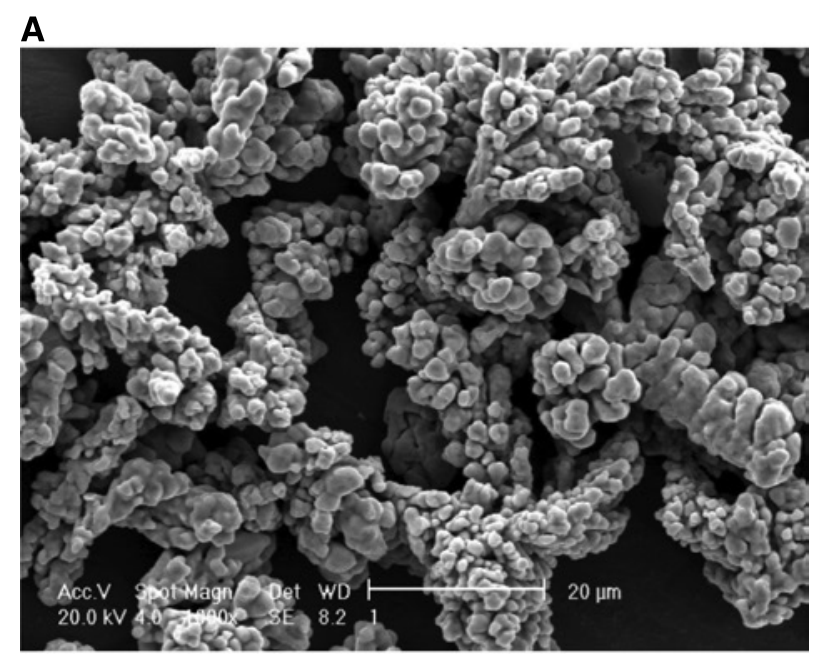

B

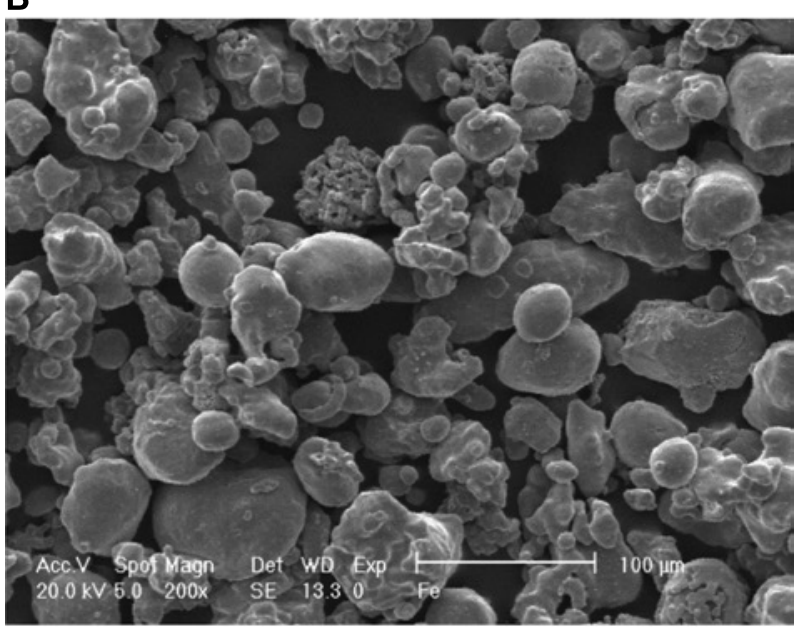

C

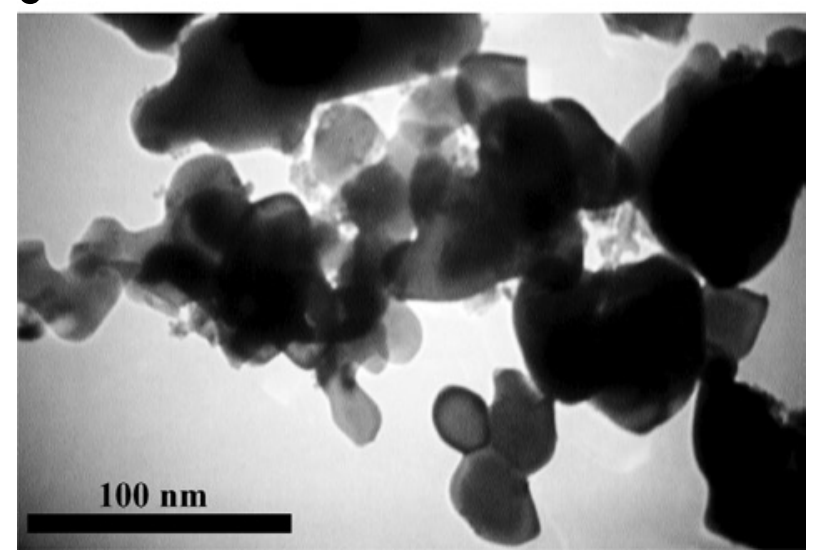

Figure 1: SEM micrograph of powder particles of (A) Cu and (B) Fe and (C) TEM micrograph of alumina nanoparticles prior to mechanical milling. 
and $\mathrm{Al}_{2} \mathrm{O}_{3}$ nanopowder were investigated by scanning electron microscope (SEM Philips XL30, Philips, Amsterdam, Netherlands) and by transmission electron microscope (TEM Zeiss EMIOC, Zeiss, Oberkochen, Germany), respectively (Figure 1).

The milled powder was pressed under the cold pressure of $350 \mathrm{MPa}$, and the green compacts with the dimensions of $25 \mathrm{~mm}$ in diameter and $3 \mathrm{~mm}$ in thickness were prepared. The green compacts were sintered in the furnace (Seco/Warwick, Poland) at a temperature of $850^{\circ} \mathrm{C}$ for 30 min under argon atmosphere. The microstructure of the sintered samples and elemental analysis were examined by a field emission scanning electron microscope (FESEM Zeiss AMA). The density of the sample was determined based on the Archimedes' law (ASTM B962). Hardness was measured using a Vickers hardness device (Zwick Roell, Ulm, Germany) with a load of $1000 \mathrm{~g}$ and a residence time of $10 \mathrm{~s}$. Tribological properties were also studied using the pin-on-disk test (Rtec, San Jose, CA, USA) by applying an $\mathrm{Al}_{2} \mathrm{O}_{3}$ pin and a normal load of $10 \mathrm{~N}$ (ASTM G99 standard). The corrosion behavior of the sintered specimens was examined by cyclic potentiodynamic polarization curves in a three-electrode cell consisting of a solution of $\mathrm{NaCl} 3.5 \%$ using the EG and $\mathrm{G}$ Instruments Inc. potentiostat (PerkinElmer, Waltham, MA, USA).

\section{Results and discussion}

Figure 2 illustrates the X-ray diffraction pattern of the $\mathrm{Cu}_{75} \mathrm{Fe}_{25}$ powder mixture at different milling durations. As specifically observed, powder mixture after 5 milling hours is related to the sharp peaks corresponding to the phases of the copper FCC and iron BCC structure. With the passage of time, the intensity of the peaks of the iron phase is diminished and then disappeared after $60 \mathrm{~h}$ of milling. The radiuses of iron and copper atoms are 0.156 and $0.145 \mathrm{~nm}$, respectively [11]. During the mechanical milling process, iron atoms are gradually introduced into the copper structure, and thereby, a copper-iron solid solution is formed. Iron atom diffusion into the copper matrix leads to an increasing parameter of the copper one, as well as a decreasing transfer of copper peak angle to the small values. As shown in Figure 2, the copper peak is shifted to lower angles indicating the iron atom diffusion into the copper matrix. After $60 \mathrm{~h}$ of milling, the peaks of iron and copper are removed, and new peaks at angles of $50.67^{\circ}, 59.17^{\circ}$, and $88.60^{\circ}$ corresponding to the copper-iron FCC phase solid solution emerge [16]. With increasing milling time, the peak width of all the elements increases despite decreasing their intensity. Peak widening is traced back to the reduction of

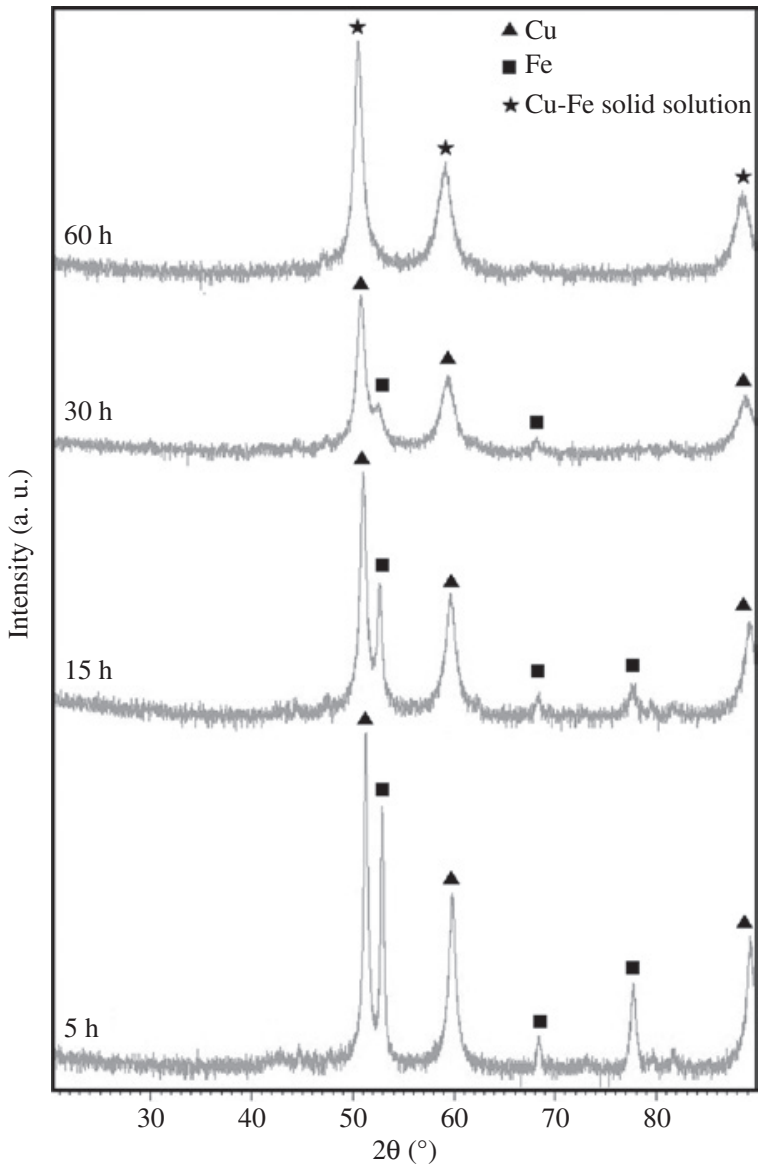

Figure 2: XRD patterns of $\mathrm{Cu}_{75} \mathrm{Fe}_{25}$ after different durations of mechanical alloying.

grain size and the rise of lattice strain [17]. In the mechanical milling process, alloying occurs at the atomic scales forming the solid solution leading to the reducing intensity of peaks in the diffraction pattern [18]. The WilliamsonHall relationship was employed to calculate the grain size through the broadening of the peaks [19]. As considerable strain is developed on the lattice during the mechanical alloying process, the Williamson-Hall method is more accurate compared to the other methods for this process. Such accuracy is explained by the fact that, in this way, both strain and fine-grained contributions are taken into account in peak broadening [20]. This relationship is presented as $\beta d=(0.9 \lambda / d \cos \theta)+\varepsilon \tan \theta$, where $d$ is the crystal size, $\beta$ is the peak width at half height, $\lambda$ is the wavelength of the X-ray, $\theta$ is the Bragg angle and $\varepsilon$ of the lattice strain. With the placement of $\beta$ in the Williamson-Hall relationship, the $\beta \cos \theta$ chart is plotted according to $\sin \theta$ and the slope of the line passing through the points expressing the existing strain in the crystals. Figure 3 demonstrates the graph of the crystalline size and the lattice strain versus the mechanical alloying time. It can be seen in Figure $3 \mathrm{~A}$ that as the mechanical alloying time passes, the crystalline size steadily decreases. 

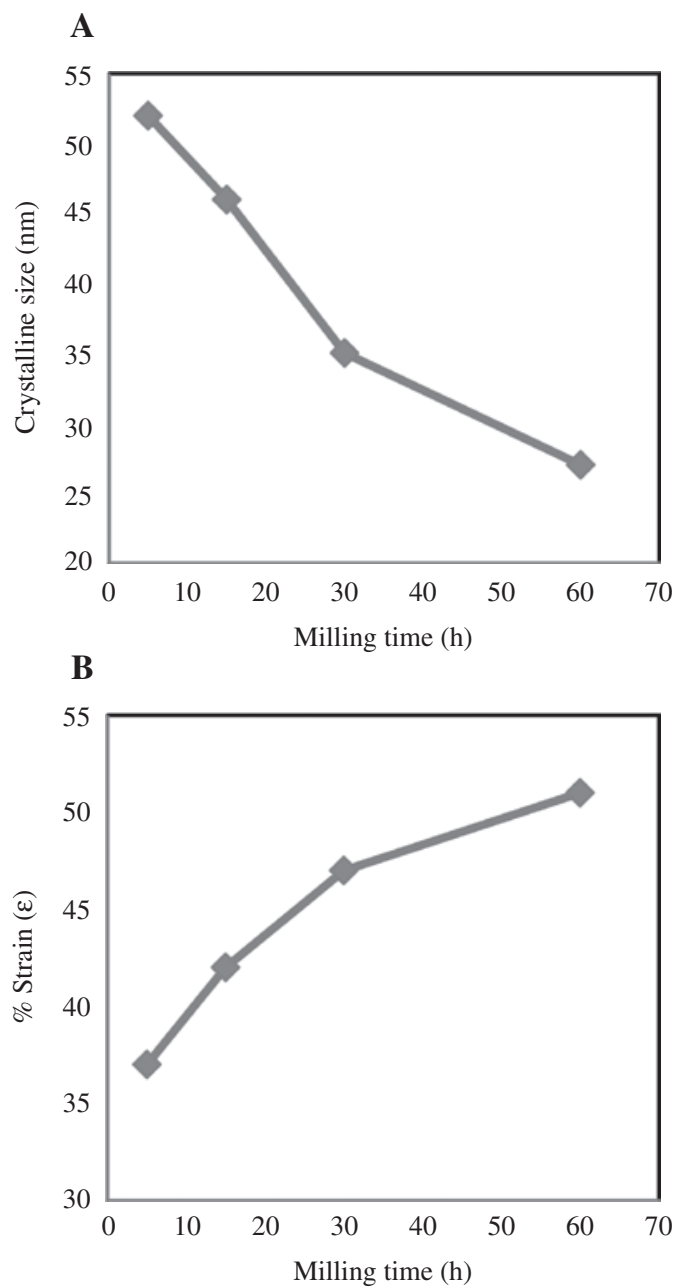

Figure 3: The increase in coercivity is attributed to the decrease in crystallite size. Variation of (A) average crystallite size and (B) lattice strain with milling time for $\mathrm{Cu}_{75} \mathrm{Fe}_{25}$ powder.

As expected, calculating the size of copper crystals indicates the fact that the severe plastic deformation applied to the powder particles during the mechanical alloying process comes down to reducing the size of the copper crystals up to $27 \mathrm{~nm}$. The final crystalline grain size obtained by milling is the outcome of the interaction between the heavy mechanical deformation of the particles and the recovery rate during the milling process [21]. At this stage, the diffusion distance of the atoms in terms of a solid solution formation is reduced [22]. Figure 3B presents the lattice strain versus the mechanical alloying time graph. As the mechanical alloying time goes on, the strain of crystalline matrix would steadily increase and reach 53\% after $60 \mathrm{~h}$. Thus, fracturing and grain rotation as the dominant mechanism for establishing stress during the mechanical milling process are expected to occur [23]. The increase in the lattice strain and dislocation density in addition to the decrease in the activation energy of diffusion leads to rising high-diffusivity paths.

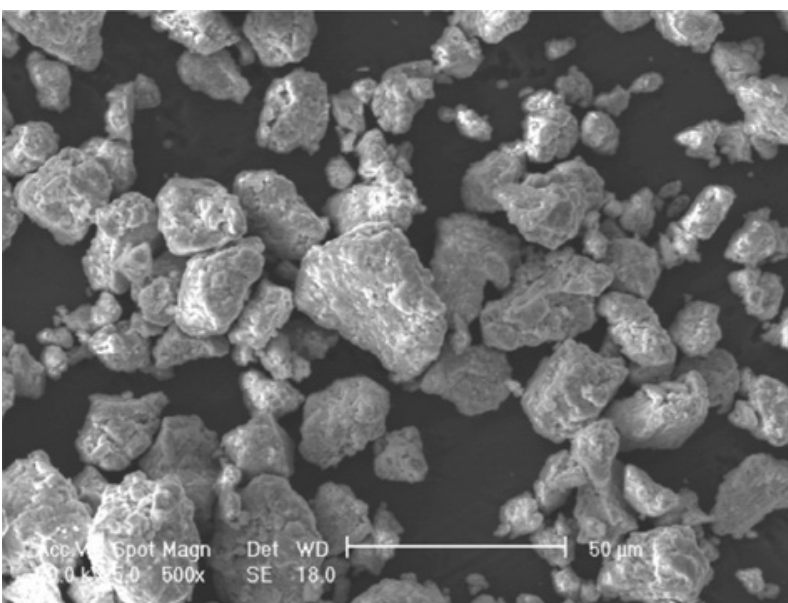

Figure 4: Morphology of CuFe(alumina) powder after $60 \mathrm{~h}$ of milling.

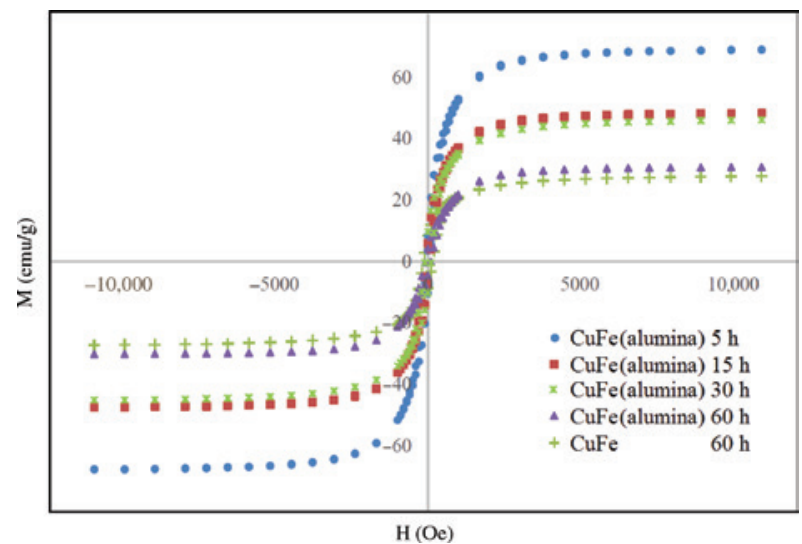

Figure 5: Magnetization versus magnetic field of CuFe alloy and CuFe(alumina) particles for different durations of mechanical alloying.

The SEM image of the powder particles after milling is shown in Figure 4. The difference in morphology and size of the powders before and after milling can be seen clearly. After $60 \mathrm{~h}$ of mechanical alloying, the particle shape becomes irregular, and the average particle size ranges approximately $10-50 \mu \mathrm{m}$. The variation of the morphology and size of the powder particles is due to the diffusion of the $\mathrm{Fe}$ and $\mathrm{Al}_{2} \mathrm{O}_{3}$ particles into the $\mathrm{Cu}$ particles during the milling process.

Figure 5 shows the room temperature ( $300 \mathrm{~K}$ ) magnetic hysteresis loops of the samples. It is clear that the magnetic saturation $\left(\mathrm{M}_{\mathrm{s}}\right)$ of the milled particles is significantly dependent on the milling time. The magnetization at $\mathrm{H}=13 \mathrm{kOe}$ decreases from 67 to $28 \mathrm{emu} / \mathrm{g}$ with increasing milling time from $5 \mathrm{~h}$ to $60 \mathrm{~h}$. Moreover, Table 1 shows the increase in coercivity $\left(\mathrm{H}_{\mathrm{c}}\right)$ of the milled nanocomposite particles with increasing milling time. The decrease 
Table 1: Summary of the magnetic properties of CuFe alloy particles.

\begin{tabular}{lrr}
\hline Milling time (h) & Ms (emu/g) & Hc (Oe) \\
\hline 5 & 8.1 & 50 \\
15 & 6.3 & 100 \\
30 & 4.2 & 150 \\
60 & 2.7 & 200 \\
\hline
\end{tabular}

in magnetization can be attributed mainly to the particle size and heterogeneity in the composition, where Fe-rich regions are considered to be the source of $M_{s}$ growth [24]. The increase in Hc is attributed to the decrease in crystallite size (Figure 3). This result revealed that the variation of Hc is strongly dependent on the particle size of the specimens obtained after each milling interval. In this way, according to Eq. (1) [25], Hc is inversely proportional to the particle size so that at 5 -h milling with greater particle size, the obtained Hc is minimum (50 Oe).

$$
\mathrm{Hc}=\mathrm{a}+\mathrm{b} / \mathrm{D}
$$

where $\mathrm{a}$ and $\mathrm{b}$ are constants, and $\mathrm{D}$ is the particle size.

As shown in Figure 5, an increase in Ms of the CuFe(alumina) sample can be seen compared to the CuFe sample with the same milling time. From this result, it seems that in the presence of the $\mathrm{Al}_{2} \mathrm{O}_{3}$ nanoparticles, the diffusion of the Fe elements in the crystal structure of the $\mathrm{Cu}$ matrix and, consequently, the Ms drop is retarded.

Figure 6 represents the SEM image of the microstructure of the sintered samples. The microstructure for both samples presents small and round pores at the grain boundaries as well as no cracks are observed. Similar results in the sintered samples using pulse electric current [26] and the conventional cold pressing sintering [27] were reported. In Figure 6, it can be seen that the number of grain boundary pores in the nanocomposite microstructure is low. In the process of metal-ceramic nanocomposite sintering, the size difference of the components influences the component diffusion coefficient and the nanocomposite sintering behavior $[28,29]$. The smaller the component size, the more the diffusion rate in the nanocomposites, and consequently, the sintering temperatures are reduced. However, the existence of $\mathrm{Al}_{2} \mathrm{O}_{3}$ nanoparticles in the metallic matrix can lead to acceleration of the diffusion process or improvement of the sintering condition [30].

As the EDX analysis results show in Figure 7, the iron and $\mathrm{Al}_{2} \mathrm{O}_{3}$ components are uniformly distributed in the copper matrix. Hence, the production of the $\mathrm{CuFe}-\mathrm{Al}_{2} \mathrm{O}_{3}$ nanocomposites is confirmed.

The relative density of both samples was measured before and after sintering and the results are shown in

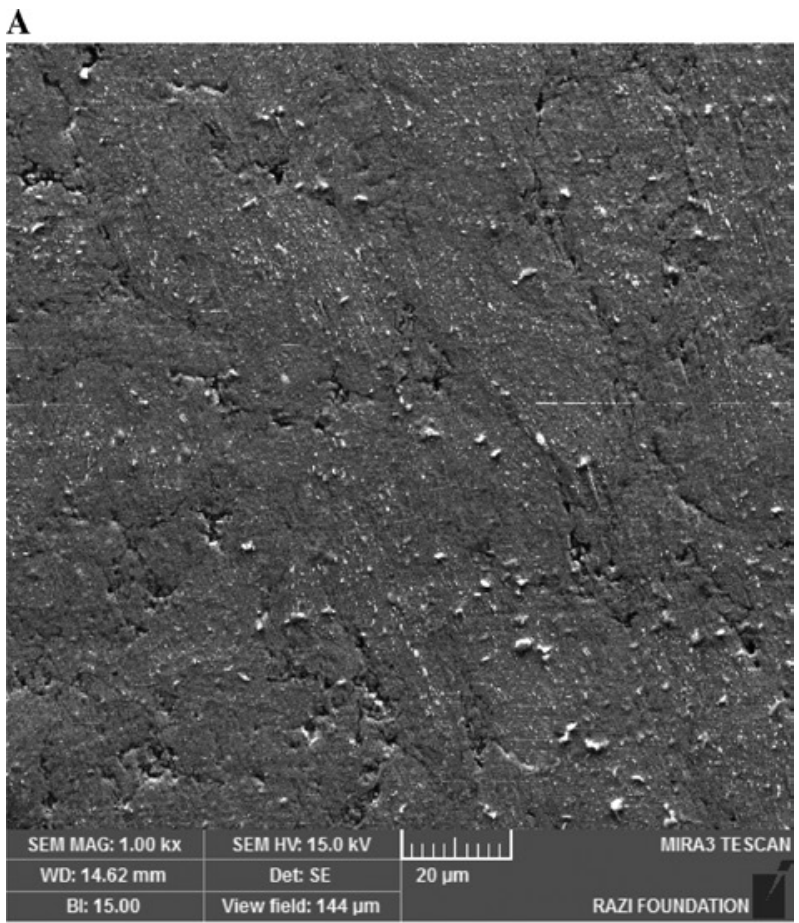

B

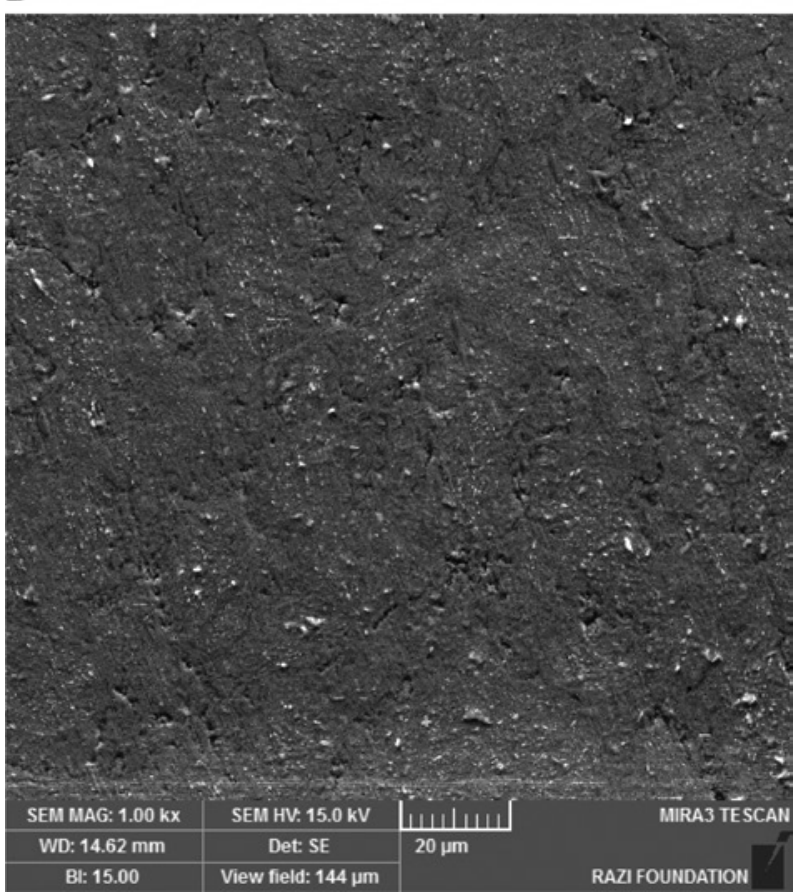

Figure 6: SEM images of cross-sectional microstructures sintered at $850^{\circ} \mathrm{C}$. (A) CuFe and (B) CuFe(alumina) samples.

Table 2. Density is an important parameter for determining the physical properties, especially dimensional stability of the samples. The relative density of the CuFe alloy was $90 \%$ and relative density of CuFe(alumina) nanocomposite was $95 \%$. It can be clearly seen that despite existing alumina nanoparticles the alloy's relative density has 

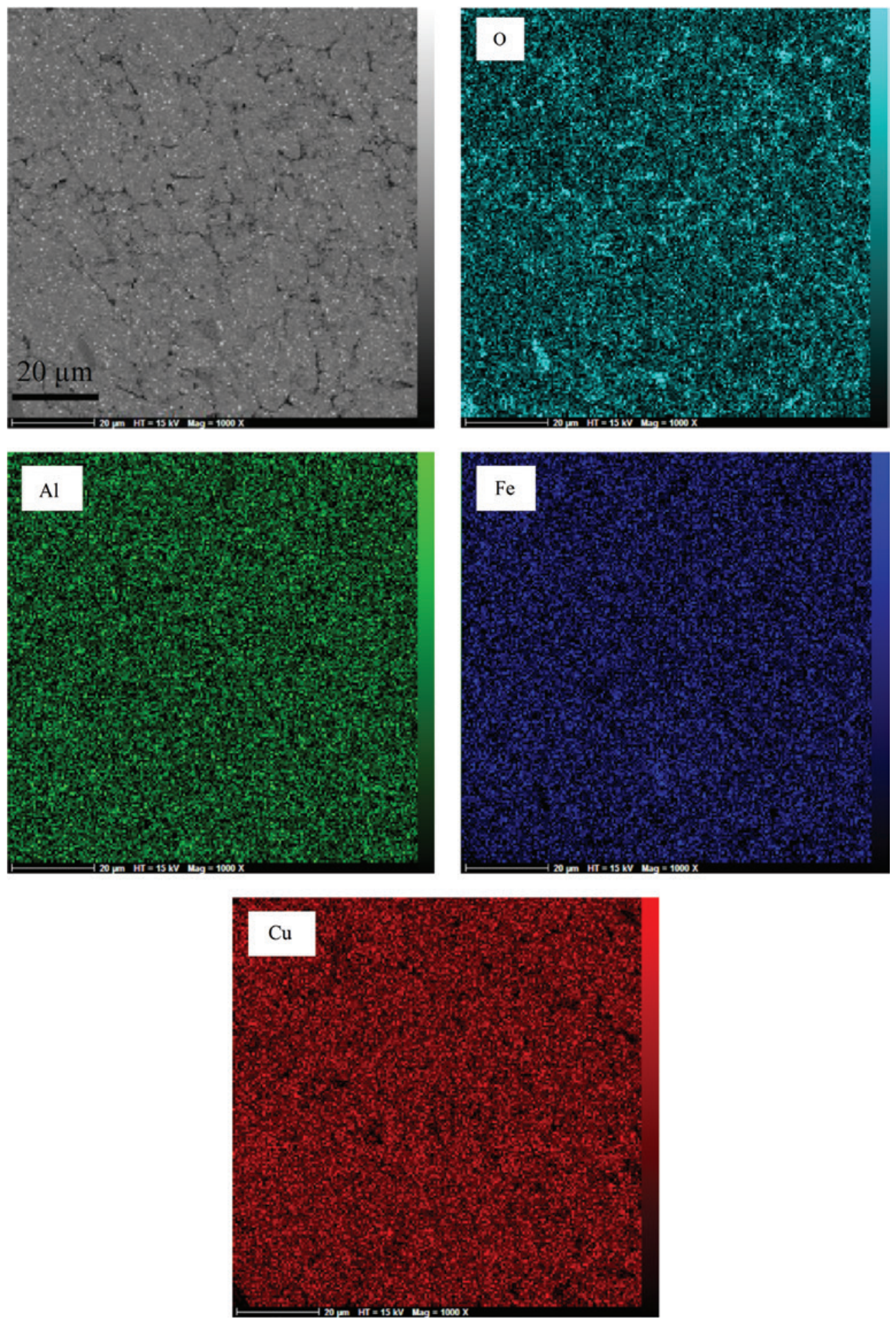

Figure 7: EDS distribution maps of $\mathrm{Fe}, \mathrm{O}, \mathrm{Al}$ and $\mathrm{Cu}$ for sample CuFe(alumina) nanocomposite.

Table 2: Density of CuFe alloy and CuFe(alumina) nanocomposite.

\begin{tabular}{lrr}
\hline Sample & Green density (\%th.d) & Sintered density (\%th.d) \\
\hline CuFe & 69 & 90 \\
CuFe(alumina) & 71 & 95 \\
\hline
\end{tabular}

(\%th.d), percentage of the theoretical density. increased by $5 \%$. The higher relative density of nanocomposite can be attributed to homogeneous distribution of alumina nanoparticles and position in the cavity located at the grain interfaces [31].

The hardness of the sintered samples is presented in Table 3. The reported values are the result of the mean 
Table 3: Microhardness of CuFe alloy and CuFe(alumina) nanocomposite.

\begin{tabular}{lr}
\hline Sample & Microhardness/HV \\
\hline CuFe & $229 \pm 7$ \\
CuFe(alumina) & $248 \pm 4$ \\
\hline
\end{tabular}

of five Vickers hardness readings. The hardness of CuFe alloy and $\mathrm{CuFe}-\mathrm{Al}_{2} \mathrm{O}_{3}$ nanocomposites are 229 and $248 \mathrm{HV}_{1}$, respectively. The results show that adding $5 \mathrm{wt} . \%$ of $\mathrm{Al}_{2} \mathrm{O}_{3}$ nanoparticles causes $10 \%$ increase in the alloy hardness. The increase in the hardness values is attributed to the dispersion hardening of the incredibly hard alumina particles with a hardness of about 1800 Vickers in the CuFe alloy matrix [32]. Based on the same research results, the uniform distribution of the $\mathrm{Al}_{2} \mathrm{O}_{3}$ hard nanoparticles opposing the displacement of the dislocations prevents the formation of plastic deformations of the matrix undertaking the load and increases the microhardness [31]. This mechanism occurs when matrix-reinforcing particles are in nanometer-size, and the volume fraction is less than 15 vol.\% [33]. Mukhtar et al. [34] prepared the $\mathrm{Cu}-\mathrm{Al}_{2} \mathrm{O}_{3}$ nanocomposites by mechanical alloying and investigated the effect of adding different $\mathrm{Al}_{2} \mathrm{O}_{3}$ nanoparticle volume fractions on the hardness. The results showed that increasing the $\mathrm{Al}_{2} \mathrm{O}_{3}$ nanoparticle volume fractions in the copper matrix increases the hardness. Maximum hardness was acquired in the nanocomposite containing 5 vol.\% (270 Vickers), and the addition of more than 5 vol. $\%$ of $\mathrm{Al}_{2} \mathrm{O}_{3}$ nanoparticles had no effect on the hardness. Shehata et al. [35] studied the effect of the addition of $\mathrm{Al}_{2} \mathrm{O}_{3}$ nanoparticles on the copper matrix. As the results show, with the addition of $12.5 \mathrm{wt} . \%$ of $\mathrm{Al}_{2} \mathrm{O}_{3}$ particles, micro-hardness was increased up to $50 \%$ and reached 80 Brinell.

Figure 8 shows the graph of the coefficient of friction (COF) for the test samples. The COFs of the CuFe alloy and the $\mathrm{CuFe}-\mathrm{Al}_{2} \mathrm{O}_{3}$ nanocomposite are about 0.75 and 0.6 ,

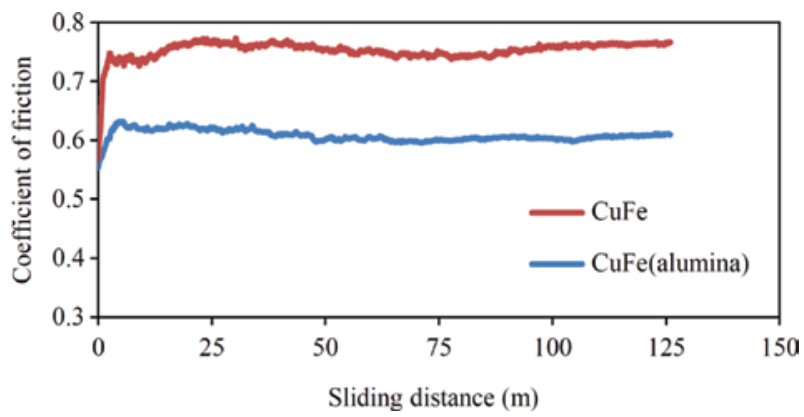

Figure 8: Coefficient of friction for CuFe alloy and CuFe(alumina) nanocomposite-sintered samples. respectively. The presence of the $\mathrm{Al}_{2} \mathrm{O}_{3}$ nanoparticles in the alloy mitigates the COF to $20 \%$. Similar results were reported by other studies, where adding alumina nanoparticles to the copper-based alloy triggers COF reduction in the wear test $[36,37]$.

Figure 9 represents the weight loss graph in the wear test. The reported values are the average of conducting the wear test four times. The weight loss rates for the $\mathrm{CuFe}$ alloy and the $\mathrm{CuFe}-\mathrm{Al}_{2} \mathrm{O}_{3}$ nanocomposites are, respectively, 0.83 and $0.57 \mu \mathrm{g} / \mathrm{N} \cdot \mathrm{m}$, indicating that the existence of the $\mathrm{Al}_{2} \mathrm{O}_{3}$ nanoparticles in the nanocomposite reduces the weight loss of about $30 \%$ in the wear test. Similar results that the addition of reinforced $\mathrm{Al}_{2} \mathrm{O}_{3}$ nanoparticles to copper-based alloys resulted in the weight loss rate reduction were reported in other studies [38-40]. In a research conducted by Fathy et al. [41] in the copper-based alloy wear test, the weight loss rate declined from 4.5 to $2.5 \mathrm{~g} / \mathrm{m}$ by adding $5 \%$ of $\mathrm{Al}_{2} \mathrm{O}_{3}$ nanoparticles. As it stands, the presence of the reinforced $\mathrm{Al}_{2} \mathrm{O}_{3}$ nanoparticles in the copperiron matrix reduced the weight loss rate. Meanwhile, the lowest coefficient of friction is related to the $\mathrm{CuFe}-\mathrm{Al}_{2} \mathrm{O}_{3}$ nanocomposite sample. As a result, the existing nanoparticles are very effective in enhancing efficiency and tribological properties of the CuFe alloy. Uniform distribution of reinforced $\mathrm{Al}_{2} \mathrm{O}_{3}$ nanoparticles in the metal matrix increases the stiffness by limiting the plate slipping dislocations leading to an increase in its hardness [42]. With increasing $\mathrm{Al}_{2} \mathrm{O}_{3}$ nanoparticles in nanocomposites, resistance to diffusion of hard abrasive particles increases (by increasing reinforced $\mathrm{Al}_{2} \mathrm{O}_{3}$ nanoparticle hardness raises); thereby, the depth of wear is reduced [43]. The reduction in the weight loss rate may be attributed to the (1) enhancement in hardness of the composite reinforced by $\mathrm{Al}_{2} \mathrm{O}_{3}$ particles and (2) greater reduction of the direct load contact between the $\mathrm{Cu}-\mathrm{Al}_{2} \mathrm{O}_{3}$ composite surface and the disk in comparison with pure $\mathrm{Cu}$ due to the load-bearing component action of hard $\mathrm{Al}_{2} \mathrm{O}_{3}$ particles [44].

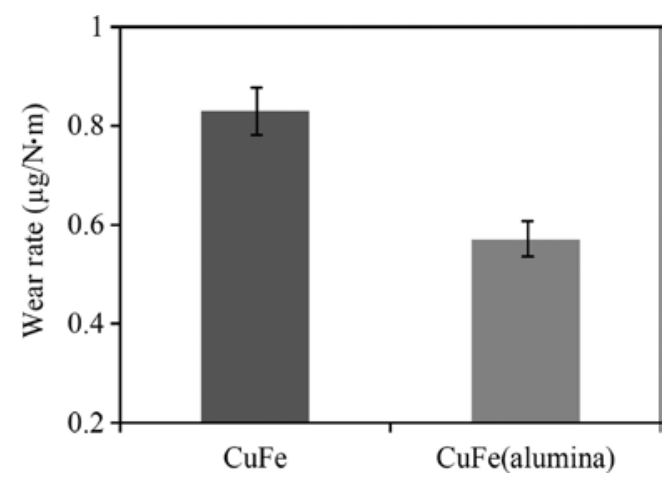

Figure 9: Wear rate data from wear tests for CuFe alloy and CuFe(alumina) nanocomposite. 
Figure 10 illustrates the SEM images of the wear surfaces. In Figure 10A, which corresponds to the copper-iron sample, the wear mechanism is adhesive because of the severe adhesion effect in the wear surfaces [32]. Accordingly, in Figure 10B, which also relates to the $\mathrm{CuFe}-\mathrm{Al}_{2} \mathrm{O}_{3}$ nanocomposite, the wear surfaces, channels parallel to the direction of wear can be seen. Thus, the dominant mechanism of this sample is abrasive wear [13]. An explanation for this abrasive wear behavior is that because of the loss of hard particle bonding existing in the composite with the matrix, hard particles are separated from the matrix, and by placing on the wear surface, not only slips on the softer surface but also damage occurs [45]. As can be seen, the existence of $\mathrm{Al}_{2} \mathrm{O}_{3}$ nanoparticles in the $\mathrm{CuFe}$ alloy metallic matrix alters the wear mechanism from adhesive to abrasive. Zhou et al. [38] reported the preparation of the $\mathrm{Cu}-\mathrm{Al}_{2} \mathrm{O}_{3}$ nanocomposites with the different volume fractions of the $\mathrm{Al}_{2} \mathrm{O}_{3}$ nanoparticles using the co-precipitation method. The

A

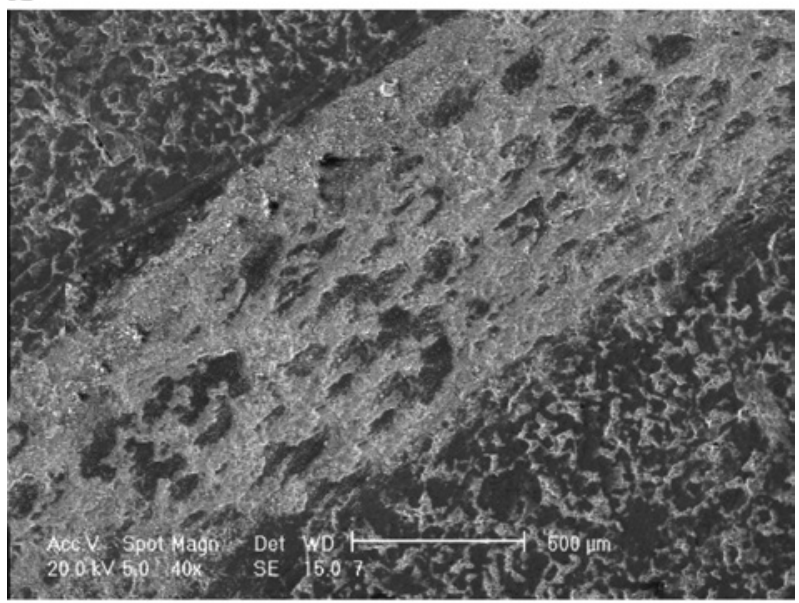

B

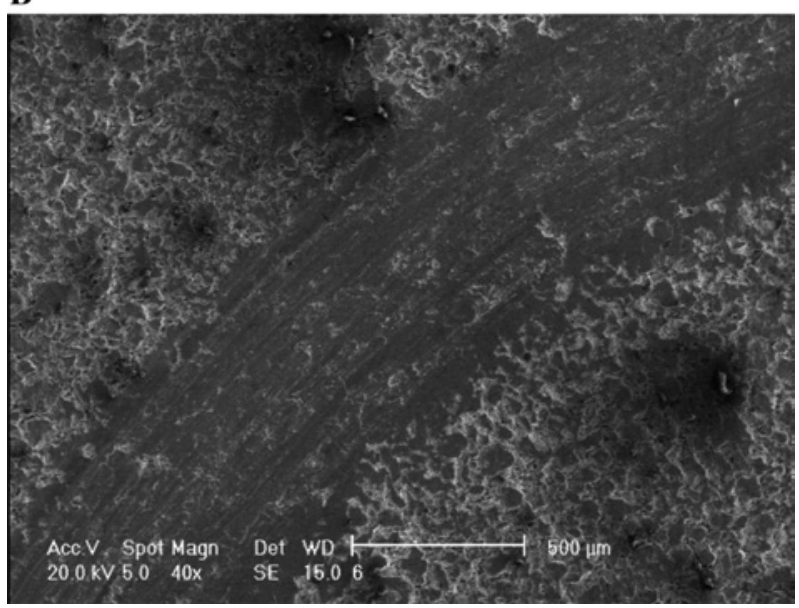

Figure 10: The SEM micrographs for worn surface of (A) CuFe alloy and (B) CuFe(alumina) nanocomposite.

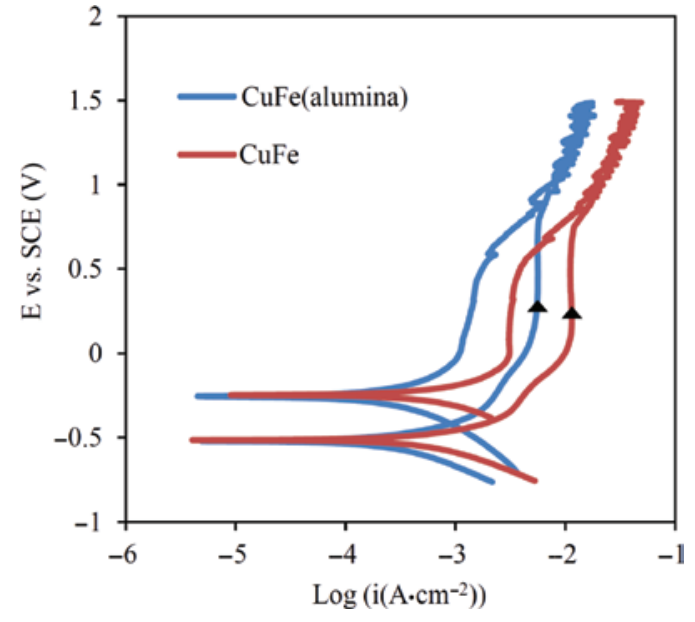

Figure 11: Cyclic potentiodynamic polarization curves of CuFe alloy and CuFe(alumina) nanocomposite in $3.5 \mathrm{wt} \% \mathrm{NaCl}$ solution.

pin-on-disk wear test results show that the copper sample presents adhesive wear mechanism. In comparison, with the addition of small amounts of $\mathrm{Al}_{2} \mathrm{O}_{3}$ nanoparticles to the copper matrix, adhesive wear with oxidation was observed. By adding greater amounts of $\mathrm{Al}_{2} \mathrm{O}_{3}$ nanoparticles (5\%), abrasive wear mechanism with layered fatigue occurred.

The corrosion behavior of the CuFe alloy and the $\mathrm{CuFe}-\mathrm{Al}_{2} \mathrm{O}_{3}$ nanocomposite was investigated using cyclic potentiodynamic polarization in a solution of $\mathrm{NaCl} 3.5 \%$ (Figure 11). Corrosion parameters such as current density, corrosion potential, anodic and cathodic slopes obtained from the polarization data are presented in Table 4. As the cyclic polarization curve is counterclockwise for both samples, and no closed hysteresis loop is observed, both samples are not susceptible to pitting. As shown in Table 4, the amounts of corrosion current densities related to the $\mathrm{CuFe}$ alloy and the $\mathrm{CuFe}-\mathrm{Al}_{2} \mathrm{O}_{3}$ nanocomposite are 631 and $158 \mu \mathrm{A} \cdot \mathrm{cm}^{-2}$, respectively. The corrosion current density of the nanocomposite is $75 \%$ less than that of the alloy. As can be seen in the polarization curves, for the $\mathrm{CuFe}-\mathrm{Al}_{2} \mathrm{O}_{3}$ nanocomposite samples, the domain of the passive area is broader than that of the CuFe samples that implies greater corrosion resistance induced by the addition of $\mathrm{Al}_{2} \mathrm{O}_{3}$. In addition, as the passive current density is

Table 4: Corrosion characteristics of sintered samples extracted from cyclic potentiodynamic polarization curves.

\begin{tabular}{lrrrr}
\hline Sample & $\begin{array}{r}\mathbf{E}_{\text {corr }} \\
(\mathbf{m V} \text { vs. SCE) }\end{array}$ & $\begin{array}{c}\mathbf{i}_{\text {corr }} \\
\left(\mu \mathrm{A} \cdot \mathrm{cm}^{-2}\right)\end{array}$ & $\begin{array}{c}\boldsymbol{\beta}_{\mathrm{c}} \\
(\mathbf{m V} / \text { decade) })\end{array}$ & $\begin{array}{r}\boldsymbol{\beta}_{\mathrm{a}} \\
(\mathbf{m V} / \text { decade) }\end{array}$ \\
\hline CuFe & -517 & 631 & 264 & 261 \\
CuFe(alumina) & -513 & 158 & 253 & 278 \\
\hline
\end{tabular}


also decreased, the presence of the $\mathrm{Al}_{2} \mathrm{O}_{3}$ nanoparticles in the alloy improves the corrosion behavior. The difference in corrosion behavior is caused by the difference existing in the microstructure. Existing oxide particles reduces the alloy's active area in contact with the corrosive environment [46]. Additionally, the surface has defects, cracks, and pores larger than the size of a micrometer. Optimal values of nanoparticles incorporated in the alloy matrix may fill these defects and prevent the dissolution of metal through the active locations [47]. Previous studies showed that the existence of ceramic nanoparticles in the alloy matrix impedes the development of pitting caused by chlorine ions [48]. The $\mathrm{CuFe}-\mathrm{Al}_{2} \mathrm{O}_{3}$ nanocomposite morphology is denser than the CuFe alloy and, therefore, exhibits a better corrosion protection performance compared to the $\mathrm{CuFe}$ alloy. In other studies, also a similar trend was reported for the impact of adding nanoparticles on corrosion performance [49]. The addition of $\mathrm{Al}_{2} \mathrm{O}_{3}$ nanoparticles within the metallic matrix enhances the inhibition effects and, consequently, increases the diffusion path distance of the corrosive agents. Therefore, the amount of water diffusion and adsorption and corrosive species would be reduced to a large extent, leading to a reduction in the amount of sample deterioration and their lifetime extension [50].

\section{Conclusion}

In this study, CuFe alloy was formed after $60 \mathrm{~h}$ of mechanical alloying. With the addition of the $\mathrm{Al}_{2} \mathrm{O}_{3}$ nanoparticles to the $\mathrm{CuFe}$ alloy, either the COF or weight loss rate was reduced by $20 \%$ and $30 \%$, respectively. The existence of the $\mathrm{Al}_{2} \mathrm{O}_{3}$ nanoparticles in the matrix of the CuFe alloy causes the wear mechanism change from adhesive to abrasive. The corrosion current density for the $\mathrm{CuFe}-\mathrm{Al}_{2} \mathrm{O}_{3}$ nanocomposite is $75 \%$ lower than that of the CuFe alloy. The morphology of the $\mathrm{CuFe}-\mathrm{Al}_{2} \mathrm{O}_{3}$ nanocomposite was denser than that of the CuFe alloy and, therefore, outperforms the $\mathrm{CuFe}$ alloy in terms of corrosion protection.

\section{References}

[1] Azabou M, Gharsallah HI, Escoda L, Suñol J, Kolsi A, Khitouni M. Powder Technol. 2012, 224, 338-344.

[2] Xie Y-P, Zhao S-J. Comp. Mater. Sci. 2011, 50, 2586-2591.

[3] Eckert J, Holzer J, Johnson W. J. Appl. Phys. 1993, 73, 131-141.

[4] Chien C, Liou SH, Kofalt D, Yu W, Egami T, Watson TJ. Phys. Rev. B 1986, 33, 3247.

[5] Bachmaier A, Kerber M, Setman D, Pippan R. Acta Mater. 2012, $60,860-871$.
[6] Verhoeven J, Chueh S, Gibson E. J. Mater. Sci. 1989, 24, 1748-1752.

[7] Sartale S, Lokhande C. Mater. Chem. Phys. 2001, 70, 274-284.

[8] Kravtsova A, Yalovega G, Soldatov A, Yan W, Wei S. J. Alloys Compd. 2009, 469, 42-49.

[9] Crivello J-C, Nobuki T, Kuji T. Mater. Trans. 2008, 49, 527-531.

[10] Ueda Y, Ikeda S, Mori Y, Zaman H. Mater. Sci. Eng. A Struct. Mater. 1996, 217, 371-375.

[11] Azabou M, Makhlouf T, Saurina J, Escoda L, Sunol J, Khitouni M. Int. J. Adv. Manuf. Technol. 2016, 87, 1-7.

[12] Brock SL. J. Am. Chem. Soc. 2004, 126, 146-179.

[13] Ying D, Zhang D. Mater. Sci. Eng. A Struct. Mater. 2000, 286, 152-156.

[14] Hwang SJ, Lee J-H. Mater. Sci. Eng. A Struct. Mater. 2005, 405, 140-146.

[15] Shehata F, Fathy A, Abdelhameed M, Moustafa S. Mater. Des. 2009, 30, 2756-2762.

[16] Baghani M, Aliofkhazraei M, Poursalehi R. Powder Metall. 2017, 1, 73-83.

[17] Cullity B. Elements of X-ray Diffraction, 2nd ed., Adisson-Wesley Publishing: USA, 1978.

[18] Fogagnolo J, Velasco F, Robert M, Torralba J. Mater. Sci. Eng. A Struct. Mater. 2003, 342, 131-143.

[19] Klung H, Alexander L. X-ray Diffraction Procedures, Wiley: New York, EUA, 1962.

[20] Suryanarayana C, Norton MG. X-ray Diffraction: a Practical Approach, Springer Science \& Business Media: Berlin, Germany, 2013.

[21] Baghani M, Aliofkhazraei M, Askari M. Int. J. Miner. Metall. Mater. 2017, 4, 462-472.

[22] Suryanarayana C. Prog. Mater. Sci. 2001, 46, 1-184.

[23] Mukhopadhyay N, Mukherjee D, Bera S, Manna I, Manna R. Mater. Sci. Eng. A Struct. 2008, 485, 673-680.

[24] Ban I, Stergar J, Drofenik M, Ferk G, Makovec D. J. Magn. Magn. Mater. 2011, 323, 2254-2258.

[25] Nguyen T. Magnetic Nanoparticles: From Fabrication to Clinical Applications, CRC: Boca Raton, FL, 2012.

[26] Goupil G, Bonnefont G, Idrissi H, Guay D, Roué L. J. Alloys Compd. 2013, 580, 256-261.

[27] Helle S, Tresse M, Davis B, Guay D, Roué L. J. Electrochem Soc. 2012, 159, E62-E68.

[28] German RM. Powder Metallurgy and Particulate Materials Processing: the Processes, Materials, Products, Properties, and Applications, Metal Powder Industries Federation Princeton: NJ, 2005.

[29] German RM. Sintering Theory and Practice. Sintering Theory and Practice, Wiley-VCH: Weinheim, Germany, 1996, pp. 568, ISBN 0-471-05786-X.

[30] Harris P. Int. Mater. Rev. 1995, 40, 97-115.

[31] Baghani M, Aliofkhazraei M, Askari M. Int. J. Mater. Res. 2017, 5, 396-405.

[32] Mangonon PL. The Principles of Materials Selection for Engineering Design, Prentice Hall: London, 1999.

[33] Rajković V, Božić D, Popović M, Jovanović M. Sci. Sinter. 2009, 41, 185-192.

[34] Mukhtar A, Zhang D, Kong C, Munroe P. Int. J. Mod. Phys. B 2010, 24, 2308-2313.

[35] Shehata F, Abdelhameed M, Fathy A, Elmahdy M. Open J. Met. 2011, 1, 25. 
[36] Jach K, Pietrzak K, Wajler A, Sidorowicz A, Brykata U. Arch. Metall. Mater. 2013, 58, 1425-1428.

[37] Vencl A, Rajkovic V, Zivic F. Proceedings of the 8th International Conference on Tribology-BALKANTRIB '14, Sinaia, Romania, 2014, pp. 30.10-01.11.

[38] Zhou G, Ding H, Zhang Y, David H, Aihui L. Metallurgia 2009, $15,169-179$.

[39] Soleimanpour A, Abachi P, Purazrang K. Tribol. Mater. Surf. Interfaces 2009, 3, 125-131.

[40] Zhang Y, Wang K, Han Z, Liu G. Wear 2007, 262, 1463-1470.

[41] Fathy A, Shehata F, Abdelhameed M, Elmahdy M. Mater. Des. 2012, 36, 100-107.

[42] Kaczmar J, Granat K, Grodzka E, Kurzawa A. Archives of Foundry Engineering 2012, 13, 33-36.
[43] Shehata F, Fathy A, Abdelhameed M, Moustafa S. J. Alloys Compd. 2009, 476, 300-305.

[44] Ramesh C, Ahmed RN, Mujeebu M, Abdullah M. Mater. Des. 2009, 30, 1957-1965.

[45] Baghani M, Aliofkhazraei M, Seyfoori A, Askari M. Trans. Indian Inst. Met. 2017, 17, 1671-1680.

[46] Sun H, Wheat H. J. Mater. Sci. 1993, 28, 5435-5442.

[47] Koivuluoto H, Vuoristo P. J. Therm. Spray Technol. 2010, 19, 1081-1092.

[48] Lampke T, Leopold A, Dietrich D, Alisch G, Wielage B. Surf. Coat. Technol. 2006, 201, 3510-3517.

[49] Almomani MA, Nemrat MH. J. Alloys Compd. 2016, 679, 104-114.

[50] Praveen BM, Venkatesha TV. Appl. Surf. Sci. 2008, 254, 2418-2424. 